\title{
Just before Watson and Crick
}

\author{
L. B. Slobodkin
}

The Watson and Crick paper essentially solved the focal question of molecular geneticists in 1953. It also impacted a spectrum of research areas that did not focus on genes themselves. I recall the response of non-geneticists to the Watson-Crick model.

Before Watson and Crick, the existence of genes could be shown using breeding experiments with mutants. These genes somehow controlled developmental and physiological events. It was clear that genes were located on chromosomes and in some cases, particular genes could be located on individual chromosomes by studies of mapping and linkage. There were even cases in which visible peculiarities of chromosomes were correlated with particular genetic properties.

Quantitative studies of DNA during chromosome reproduction had made it clear that DNA replicated itself, that this was associated with coiling and that it occurred in or on chromosomes.

With all this, the word 'gene' had no physical reference point. Although genes were associated with particular locations on particular chromosomes, the genes were not visible-they were localized properties of chromosomes, but they were beyond microscopic resolution. A gene was a theoretical entity that met a set of empirical restrictions. It was felt that for many purposes the actual physical properties of the genes did not matter. Hypothetical genes were still useful.

Because different mutations affected different steps in biochemical syntheses, some biochemical processes, like pigment synthesis, could be unraveled. Because they were in a linear order, genes could be mapped like towns on a long highway in favorable crossover studies. Chromosomes with identical linear gene maps were identical chromosomes, no matter where they were found. This permitted clear indication that speciation had occurred, and combined with study of overlapping inversions of order in parts of the chromosome, maps provided unique, if unrooted, phylogenetic trees indicating relations among populations within single species and, in some cases, among species.

Study of karyotypes and ploidy also provided some clear phylogenetic inferences without ever knowing particular genes.

In short, there were studies of the activities of genes and the role of genes in biochemical syntheses, ecology and evolution before Watson and Crick, but these were limited by the absence of tangible genes. This absence permitted fairly free speculation. The genotype could be imagined in many forms. There were serious discussions of hypothetical gene plasms, linear crystals and integrated 'holistic' assemblages.

There were invocations of 'genetic influences', often with no regard to genetic mechanisms, of the sort that occur even now in loose applications of genetics to social sciences. For example, the historian Richard Pipes concluded in 1996 that Communism had to disappear because it "violated everything we have learned from sociobiology, anthropology and the psychology of human nature, the building blocks of every social order." (Bull. Am. Acad. Arts Sci. 49, 39-53 (1996)).

One of the strongest areas of evolutionary genetics then and now was 'population genetics', a complex of mathematical models in which selection, mutation rates of various kinds, linkage patterns and assumed population distributions and mating systems produced changes of gene-frequency distribution with the passage of time.

The absence of a clear sense of the physical nature of actual genes was accompanied in 1953 by a startling absence of computational ability. Theories of evolutionary genetics relied more heavily on a combination of simplifications and sophisticated mathematics than on numerical simulations. This combination of simplifying assumptions, computational weakness and complex mathematics generated a curious sub-field of applied mathematics that did not quite present testable empirical hypotheses but purported to provide insights. A recurring question about population genetics then was "Insight into what?" Population genetics became predictive by use of DNA sequence data.

Did ecologists and evolutionists see all this changing when the Watson and Crick paper first came out? Perhaps not in detail, but we knew that something terrific had happened. Almost immediately, DNA similarities and differences between organisms were directly examined using new chemical techniques. Now high school honors classes are taught to do determinations of DNA similarity that might have won them Nobel prizes in 1955.

In 1953 I was an instructor at the University of Michigan, teaching a non-majors first-year zoology course. When the replication model appeared, I designed a kind of ballet for 24 students in a laboratory class in which each student was assigned the name of one of the four nucleotide bases, and by coming together, separating, finding appropriate partners and reassembling, they could act out the replication process for a small DNA chain. I forget the details but it did work. This may have been one of the first attempts to teach an elementary class how DNA replicated.

Watson was invited to speak at our regular Wednesday department seminar in Ann Arbor, and after his excellent lecture I described my lab exercise to him, touting it as important for beginning students' understanding. My recollection is that he did not respond verbally, but his face seemed to express complete disgust with me and my little exercise. At the time I thought that perhaps he felt that such an important idea should not be taught in such an elementary way. I remember thinking that he may well have been correct. Of course, within months DNA had entered general consciousness so completely that junior high school children were building jokes about complex spirals and punning 'jeans' and 'genes'.

Before the concretization of genes, there was endless room for speculation about gene-phenotype interaction. With real chemical 
genes, gene-phenotype interaction would clearly be shown to be a matter for biochemical genetics to work out. To a large extent, this proved valid, but uncomfortable areas remained. Chemical reactions, particularly organic chemical reactions, are enormously sensitive to concentrations of ancillary chemicals, folding state of molecules, rates of competing reactions and other factors. And particular DNA sequences have been found to control or at least influence the result of activities on other genes. The fact that similar homeobox genes are involved, on at least one level, in the formation of heads in hydra, flies and mice seems to contradict some of the anticipated simplicity in the relation between DNA and phenotype. In fact, the relation between clearly defined chemical DNA and actual morphological and behavioral phenotype is still the central focus of developmental genetics.

In the months immediately after the Watson and Crick paper was published, every university wanted its own, suitably modified, Jim Watson. Every young biologist had decisions to make. We had been shown a main path to the future of biology. Should we drop all other projects to follow this magnificent lead? Some thought so. But most took the position that although DNA research might prove wonderfully exciting, they rather enjoyed the work they had been doing and were interested in continuing. I was concerned with population dynamics and energetics in zooplankton at the time, and it never really occurred to me that analysis of DNA would answer questions in this area. In fact, it has not. Nor has it answered direct questions about most problems of morphology, behavior or ecology.

When DNA bases of different organisms were sequenced, it became possible to build phylogenetic trees, almost free of debate. Phylogeny, which had relied on the intuitive expertise of museum morphologists, became an eminently practical and objective enterprise. Development of a phylogenetic tree for all species is now a practical and finite, albeit Herculean, job. Phylogeny is arguably the evolutionary subject that has been most revised by DNA data, but the methodological revision extended over a forty year period.

Understanding of DNA and its function left some large problems unresolved and did not replace certain long-established procedures. Agronomy, animal husbandry and crop breeding are obviously aspects of genetics. Should all young crop breeders become adept in DNA? Eventually, perhaps; but selection and careful breeding had done very well before DNA replication was understood and are still useful without detailed knowledge of DNA sequences. DNA guides all that is done by organisms, but the organisms are also interesting on their own.

Academic strife between those who felt that research that is not focused on the consequences of particular DNA sequences is passé and those who insisted on focusing on the properties of whole organs and even organisms began almost immediately. There was re-allotment of funds, space and faculty lines to accommodate the new science, often at the cost of more traditional aspects of biology. The resulting conflict split some departments and eliminated others, and it recurs in many universities whenever departments are reorganized. Often two or more departments of biology exist in a single university-some looking back to Watson and Crick as their intellectual founders while others look back to Darwin and Wallace. Fortunately, a more eclectic and intellectually satisfying position in which DNA sciences and techniques enrich organismal studies while study of organisms poses problems for genetic analysis has been imposed on most biological research institutions by an abundance of common sense and a shortage of money. 